DOI: $10.17805 / z p u .2016 .3 .28$

\title{
Карьерные планы старшекурсников и требования рынка труда: проблема соответствия
}

\author{
М. С. КОРОТКОВА \\ (МОСКОВСКИЙ ГУМАНИТАРНЫЙ УНИВЕРСИТЕТ)
}

Вхождение молодежи в социально-экономическое воспроизводство общества происходит в кризисной ситуации, осложненной сокращением рабочих мест, задержкой выплаты заработной платы, сокращением рабочей недели, несоблюдением трудового законодательства. Если добавить к этому увеличенные требования работодателей, то процесс поиска работы и само трудоустройство представляют собой сложное испытание, требующее особой подготовки соискателей. 
Анализ результатов исследования карьерных планов старшекурсников Московского гуманитарного университета (в опросе приняли участие 168 бакалавров выпускных курсов), проведенного в конце 2015 учебного года Центром содействия трудоустройству выпускников МосГУ, позволил выявить проблемы, препятствующие успешному трудоустройству выпускников.

Труд остается значимым фактором личностного самоопределения значительной части выпускников. Половина старшекурсников планируют пойти работать по специальности, имея опыт работы в осваиваемой сфере во время учебы.

Отличительной чертой мотивации труда молодежи является ее инструментализация: для трети выпускников не так важна специальность, сколько заработная плата, которую предложат на новом месте. Установлены корреляции между желаемым уровнем заработной платы и направлением обучения выпускников: зарплатный максимум установлен в группе студентов-международников, впоследствии более других испытывающих трудности в поиске работы.

Чрезмерная амбициозность при отсутствии опыта, отсутствие блеска в глазах, системности мышления и понимания своей нужности в организации - основные причины отказа работодателей. Собственное время и комфорт представляются респондентам более ценными критериями поиска работы, нежели ожидание интересной работы и развитие профессиональных качеств.

Результаты исследования свидетельствуют о неподготовленности старшекурсников к поиску работы, непониманию ситуации на рынке труда, незнанию требований работодателей. Решение перечисленных проблем составляет основное поле деятельности Центра содействия трудоустройства выпускников МосГУ.

Ключевые слова: трудоустройство; выпускники вуза; студенты; старшекурсники; выбор профессии; рынок труда; карьерная стратегия

\section{BВЕАЕНИЕ}

$\Pi$ оложение молодежи в сфере труда характеризует ее включенность в трудовые отношения, устремления в сфере труда, способность быть субъектом экономического воспроизводства. От того, насколько молодежь подготовлена к процессу трудоустройства, в какой мере мотивирована трудиться, что ожидает от трудовых отношений и какими возможностями обладает для реализации своих ожиданий, зависит развитие и самой молодежи, и всего общества (Зубок, Ростовская, Смакотина, 2016: 74).

Вместе с изменением экономической ситуации на российском рынке труда, характеризующейся уменьшением числа рабочих мест, сокращением рабочей недели, вынужденными отпусками, усложнились условия вхождения молодежи в процесс экономического воспроизводства, увеличились требования со стороны работодателей, к которым выпускники вузов оказались не готовы или их к этому не подготовили. Завершив учебу в университете, вчерашний студент оказывается один на один с проблемой трудоустройства: вуз уже не несет за него ответственность; работодатель не готов брать молодого сотрудника без опыта работы, вкладываться и доучивать его; государство обеспечит минимум своего внимания выпускнику только в статусе официального безработного, зарегистрированного на бирже труда.

\section{ОШИБКИ ПРИ ТРУАОУСТРОЙСТВЕ}

Во многом проблема трудоустройства выпускников связана с отсутствием у них понимания того, что процесс поиска работы - тоже работа, требующая особой подготовки. Отложенный процесс поиска работы зачастую спровоцирован завы- 
шенными ожиданиями выпускников, низкой ответственностью, нежеланием реализовать профессиональный потенциал и неумением планировать карьеру. Аля построения успешной карьерной стратегии необходимы все вышеперечисленные составляющие и комплекс профессионально значимых качеств.

Составление карьерного плана, следование стратегии личностного профессионального роста свойственно единицам. Отсутствие мотивации в учебе, пассивное пребывание в статусе студента на протяжении четырех лет не предполагает инициативности в вопросе построения карьеры. Результаты исследований портала Superiob подтверждают эту мысль: 30\% вчерашних студентов предпринимают активные шаги сразу после получения диплома. Подавляющее большинство оставляет вопрос поиска работы на осень (Иетом шансы найти ... : Электронный ресурс).

Отсутствие практики подготовки к трудоустройству, карьерной стратегии, реального плана действий для достижения успеха и желаемого социального статуса приводят к разочарованию на первых этапах поиска работы, неуверенности в себе, работе не по специальности, частой смене места работы, неудовлетворенности выбранной позицией (Резник, 2002: 83).

\section{КАРЬЕРНЫЕ ПААНЫ И ОЖИААНИЯ ВЫПУСКНИКОВ МОСГУ}

На основании результатов опроса выпускников Московского гуманитарного университета, проведенного в мае 2015 г. нами в Центре содействия трудоустройству выпускников, выявлены проблемы, с которыми сталкиваются студенты старших курсов при поиске работы, и условия, препятствующие успешной стратегии поведения на рынке труда.

В опросе приняли участие 168 бакалавров выпускных курсов факультетов экономики и управления (46 студентов, 27\%), психологии и социальной работы (33 студента, 20\%), международных отношений и туризма (38 студентов, 23\%), культуры и искусства (28 студентов, 17\%), юридического факультета (23 студента, 14\%).

На момент окончания университета только половина старшекурсников (52\%) планировали пойти работать по специальности. Можно по-разному интерпретировать мотивы таких планов: неосознанный выбор специальности / направления обучения, разочарование в процессе учебы, невостребованность профессии или отсутствие знаний о вариативности ее применения, изменение жизненных обстоятельств. В любом случае, работа не по профилю подготовки будет требовать от выпускников дополнительных временнь́х и, возможно, денежных затрат на переподготовку. Профессиональный старт и продвижение по карьерной лестнице этой группы респондентов будут несколько отдалены по времени.

Аля трети респондентов (33\%) не так важна специальность, сколько зарплата, которую предложат на новом месте. В ситуации усиливающегося социально-экономического кризиса, резкого углубления дифференциации доходов они выберут материальный достаток.

Меньше четверти опрошенных $(16,2 \%)$ хотели бы связать свое будущее с предпринимательской деятельностью. В стремлении выпускников стать предпринимателями проявляется риск и желание развивать собственное дело. Работа, деньги, свое дело, наличие своего бизнеса - отражение молодежного прагматизма и расчетливости. Вряд ли за это можно осуждать студенческую молодежь: сложное материальное положение многих студентов, отсутствие достаточных мер социаль- 
ной защиты этой социальной группы предопределяют выбор молодежью прагматичной стратегии на материальные блага.

На продолжение своего образования в магистратуре, аспирантуре или получение второго высшего образования ориентированы 19\% старшекурсников. Среди данной группы респондентов сильна терминальная составляющая образования, ценность представляет знание как таковое, а не возможности, открывающиеся с помощью него.

Меньшинство составили респонденты, планировавшие уехать за границу (8\%), и фаталисты, выбравшие вариант ответа «буду жить как получится» (7\%). Карьерные стратегии первых будут реализованы за пределами Российской Федерации, для вторых не так и важно, будут ли они осуществлены в принципе.

Ответы на вопрос о наиболее предпочтительном жизненном пути представлены в табл. 1.

Таблича 1

РАСПРЕАЕ АЕНЕ ОТВЕТОВ НА ВОПРОС О ПРЕАПОЧТИТЕАЬНОМ ЖИЗНЕННОМ ПУТИ, \%

Table 1

DISTRIBUTION OF ANSWERS TO THE QUESTION: «WHAT DO YOU PLAN TO DO AFTER COMPLETING THE CURRENT EDUCATIONAL PROGRAM?», \% (SEVERAL CHOICES ALLOWED)

\begin{tabular}{|c|c|}
\hline $\begin{array}{c}\text { Какой жизненный путь представляется Вам } \\
\text { наиболее предпочтительным после завершения своего образования? }\end{array}$ & Количество \\
\hline Пойду работать по полученной специальности & 1,4 \\
\hline Буду искать место, где хорошо платят & 32,9 \\
\hline Буду пытаться создать собственное дело & 16,2 \\
\hline Буду жить как получится & 6,9 \\
\hline Постараюсь уехать за границу & 8,1 \\
\hline Поступлю в магистратуру или аспирантуру & 18,5 \\
\hline Получу второе высшее образование & 13,3 \\
\hline
\end{tabular}

Примечание. При ответе на вопросы данного исследования респонденты могли выбрать несколько вариантов ответа.

Число старшекурсников, которые уже работали на момент выпуска из университета $(45,4 \%)$, и тех, кто работы еще не имел $(54,6 \%)$, оказалось примерно равным. Из числа первых $65 \%$ трудились по своей специальности. Эту категорию работающих студентов можно назвать профессионально ориентированными прагматиками, обладающими высокой трудовой мотивацией и более других адаптированными к современным условиям рыночной экономики.

Труд остается немаловажным фактором личностного самоопределения для большинства молодежи. Значительная часть молодых людей связывает с ним свою нынешнюю и дальнейшую жизнь. Результаты исследования подтверждают эту мысль - абсолютное большинство респондентов (80\%) выразили готовность работать полный рабочий день. При этом часть из них была согласна на частичную занятость (28\% от общего числа респондентов). Молодые люди высоко ценят свое 
время, в том числе и свободное. Режим рабочего времени - второй критерий после заработной платы, на который обратит внимание чуть больше половины выпускников при выборе работы (58\%).

В выборе способов поиска работы выпускники предпочитают обращаться к ресурсам сети Интернет (70,4\%). Аополнительно они могли отмечать и другие варианты. К знакомым и родным планируют обратиться больше половины респондентов (58\%). В только созданный Центр содействия трудоустройству выразили желание обратиться 13\% выпускников. Вопрос был полузакрытым, и респонденты указывали свои варианты ответов: «работа сама меня найдет», «специальные журналы», «биржа труда», «через преподавателя» и др.

Отличительной чертой мотивации труда молодежи является ее инструментализация. В отношении к труду и профессии у большинства выпускников, как мы уже выяснили, доминируют прагматические ценности. Прочная связь труда и заработка сформировалась у большинства выпускников: первое, на что они обращают внимание при поиске работы, - заработная плата $(86,2 \%)$.

Ответы на вопрос о том, что для выпускников представляется главным при выборе работы, представлены в табл. 2.

Таблища 2

РАСПРЕАЕАЕНИЕ ОТВЕТОВ НА ВОПРОС О ПРИОРИТЕТАХ ПРИ ВЫБОРЕ РАБОТЫ, \%

Table 2

DISTRIBUTION OF ANSWERS TO THE QUESTION "WHAT ARE THE MOST IMPORTANT FACTORS

IN CHOOSING A IOB?”, \%

\begin{tabular}{|l|c|}
\hline \multicolumn{1}{|c|}{ При выборе работь основное значение имеет } & Количество \\
\hline Заработная плата & 86,2 \\
Режим рабочего времени & 57,5 \\
Отношения в коллективе & 47,1 \\
Работа по специальности & 37,4 \\
Близость к дому & 25,3 \\
Моральное удовлетворение от работы & 19 \\
Одобрение родителей & 1,7 \\
\hline
\end{tabular}

Зарплатные ожидания выпускников выглядят совсем не скромно. При отсутствии опыта работы и практических навыков треть студентов $(32,2 \%)$ удовлетворит зарплата в диапазоне от 50 до 60 тыс. руб., еще треть респондентов (31\%) оценивают себя на рынке труда свыше 80 тыс. руб. Чуть меньше четверти опрошенных $(19,3 \%)$ согласны на зарплату от 35 до 45 тыс. руб. Эта сумма считается более реальной для молодых специалистов на самых распространенных должностях (экономиста, PR-менеджера, копирайтера), по данным аналитиков Исследовательского центра Superiob (Зарплата 2013: Электронный ресурс).

В ответах респондентов заметны некоторые корреляции при распределении по факультетам: самые скромные зарплатные ожидания свойственны старшекурсни- 
кам юридического факультета. Зарплатный максимум отмечен в ответах студентов факультета международных отношений и туризма. Заметим, что впоследствии выпускники именно этого факультета более других испытывают сложности с трудоустройством. Считая своими конкурентными преимуществами знание двух и более языков, участие в международных стажировках, учебу по обмену, студенты этого факультета склонны оценивать себя выше других на рынке труда, однако при поиске работы чаще других сталкиваются с отсутствием рабочих мест, вызванным закрытостью дипломатического корпуса, и, как следствие, работают не по специальности.

По результатам онлайн-опроса, проведенного 19-23 апреля 2012 г. порталом для молодых специалистов Career.ru среди 709 российских студентов и молодых специалистов, завышенные зарплатные ожидания - одна из основных причин отказа молодежи в работе еще на этапе собеседования. Ааже не отсутствие опыта, а чрезмерная амбициозность, желание получать все и сразу, расчет на легкие деньги провоцируют сложности на старте карьеры (Качество образования: Электронный ресурс).

К сожалению, у старшекурсников отсутствует понимание того, что не соискатели, а работодатель устанавливает зарплатный потолок. Конечно, выпускники на рынке труда - «продавцы» своих способностей, опыта, знаний, но их первостепенная задача - научиться ориентироваться на этом рынке, почувствовать спрос, создать достойное предложение, выгодно продать его по адекватной цене и получить возможность заниматься любимым делом и развиваться в профессии, а не установить ценник и ждать очереди предложений.

Рассматривая работодателя только с позиции зарплатодателя, выпускник не стремится доказать на собеседовании, что его способности, знания, умения и качества могут быть полезны для достижения общих целей организации. И здесь важно, чтобы специальность, полученная в университете, была привлекательной и интересной для самого выпускника, обеспечивала тот самый блеск в глазах, который хотят видеть рекрутеры на собеседовании.

Возможность самореализации, социальный статус, материальное благополучие, психологическое здоровье, удовлетворение духовных потребностей, стиль жизни молодых специалистов будут зависеть от того, где, в какой организации, в каком окружении они будут работать (Чередниченко, 2004: 56). Практически половина старшекурсников считают важным при поиске работы отношения в коллективе $(47 \%)$.

Менее трети выпускников связывают с трудом ожидание интересной работы, свою полезность, развитие профессиональных качеств. Такие ценные для работодателей ответы, как «моральное удовлетворение от работы», «главное - принести пользу организации», оказались в числе последних позиций, уступая позиции «близость работы к дому» (25\%). В последнем ответе проявляются такие ценные для респондентов факторы, как время и комфорт. Можно предположить, что, выбирая университет по критерию близости расположения к дому, выпускники и при выборе места работы считают этот пункт значимым.

При переходе от одного вида деятельности к другому, от учебы к работе, естественным представляется возникновение ситуации неопределенности, появление разнообразных проблем при трудоустройстве (табл. 3, с. 334). Половина респондентов указывают в числе первых проблем трудоустройства отсутствие вакансий 
(54\%), а половина (55\%) - низкий уровень оплаты труда по сравнению с желаемым. Почти четверть видят сложность в подборе вакансий $(20,2 \%)$ и неподходящем графике работы $(26,2 \%)$. В поле «другое» респонденты записали ответы: «отсутствие английского языка», «дальность», «наличие маленьких детей»и др.

Таблииа 3

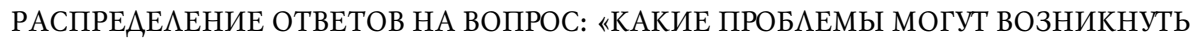
ПРИ ТРУАОУСТРОЙСТВЕ?», \%

Table 3

DISTRIBUTION OF ANSWERS TO THE QUESTION:

«WHAT PROBLEMS MAY ARISE IN GETTING A IOB?», \%

\begin{tabular}{|l|c|}
\hline \multicolumn{1}{|c|}{ Какие проблемъ могут возникнуть при трудоустройстве } & Количество \\
\hline Отсутствие вакансий & 53,6 \\
Низкий уровень оплаты труда & 54,8 \\
Неподходящий график рабочего времени & 26,2 \\
Сложность в подборе вакансий & 20,2 \\
Отсутствие навыка самопрезентации & 10,7 \\
Сложность в написании резюме & 4,8 \\
Эмоциональные переживания & 20,2 \\
\hline
\end{tabular}

\section{ПОАГОТОВКА К ПОИСКУ РАБОТЫ}

Позиции «сложность в подборе вакансий», «отсутствие навыка самопрезентации», «сложность в написании резюме» указали единицы. Создается впечатление, что на рынок труда выходят уверенные в себе, самостоятельные соискатели с набором профессионально значимых качеств, владеющие технологией трудоустройства, с выстроенной стратегией поиска работы и при этом не оцененные работодателями по достоинству. Тогда почему из раза в раз встречаются факты отказа в приеме на работу выпускников вузов? Почему работодатели недовольны качеством подготовки вчерашних студентов и предъявляют к ним целый комплекс требований: наличие трудового или даже собственно профессионального опыта, умение работать в команде, развитые специальные компетенции и т. А.? В этих условиях даже хорошо подготовленным выпускникам вузов не гарантировано трудоустройство. Многие из них вынуждены начинать трудовую деятельность, еще обучаясь в вузе, часто в ущерб качеству образования, которое необходимо для их успешного устройства на работу (Аудина, Семенова, 2015: 18).

Отсутствие навыков поиска работы приводит к ошибкам на первых же его этапах - резюме выпускников часто не соответствуют требованиям работодателей. Среди наиболее распространенных ошибок - орфографические и технические ошибки в оформлении текста, отсутствие логики изложения, а также конкретной должности, на которую претендует соискатель.

Как самостоятельные агенты рынка труда, выпускники должны сформировать для себя определенную карьерную стратегию или, если угодно, стратегию выжи- 
вания (Аавыдова, 1999: 20). Речь идет и о психологической готовности к трудоустройству, адекватном восприятии проблемы собственной занятости, и реальном видении перспектив решения этой проблемы.

В ситуации, когда руководители компаний готовы особенно тщательно рассматривать каждого кандидата и безжалостно отсеивать претендентов, резюме - документ, заочно представляющий соискателей, их навыки, умения, опыт. Как написать яркое, содержательное и нешаблонное резюме для того, чтобы рекрутер крупной компании, просматривающий в день до 500 подобных резюме, смог уделить твоему документу всего 30 секунд и заметить? Как подготовить себя к дистанционной оценке работодателя: решению кейсов, творческих заданий, деловой игре? Процесс собеседования и вовсе можно сравнить с прыжками через горящий обруч, к которым не всегда должным образом готовы выпускники.

Определив для себя проблемное поле выпускников при поиске работы, Центр содействия трудоустройству выпускников МосГУ под руководством автора статьи сформулировал для себя новые направления работы в 2016/2017 учебном году, в том числе такие, как регулярные мастер-классы по написанию резюме, прохождению собеседования, технологиям поиска работы, карьерному планированию, навыкам самопрезентации. За первый год работы Центра участниками мероприятий по содействию трудоустройству стали 564 студента, трудоустроены на постоянную работу 23 человека, на так называемую подработку - 44 студента дневной формы обучения.

При всей сложности и неоднозначности положения выпускников на рынке труАа их социальное самочувствие достаточно оптимистично: половина опрошенных (49\%) выбрали следующую позицию: «Жизнь прекрасна: чувствую себя уверенно, все в моих руках». Есть среди выпускников МосГУ и реалисты-практики, они составили почти половину респондентов $(42,6$ \%) и выбрали такой ответ: «Предстоит решить много задач, но я с ними справлюсь».

\section{ЗАКАЮЧЕНИЕ}

Позитивный настрой выпускников в вопросе трудоустройства сочетается с совершенно четкой ориентацией на материальные ценности. Инструментализация мотивов труда выражается в том, что самоценное отношение к труду с точки зрения его содержания все больше вытесняется отношением к нему как к средству достижения других целей.

В ситуации, когда сам выпускник оказывается самым заинтересованным и ответственным за свое трудоустройство лицом, университет является лишь стартовой площадкой, где одновременно идет освоение содержательного аспекта учебных планов и практического опыта по технологии трудоустройства. Сочетание двух компонентов и самостоятельная заблаговременная подготовка к поиску работы дадут положительный результат, выраженный в сформированной карьерной стратегии.

\section{СПИСОК АИТЕРАТУРЫ}

$\Lambda$ етом шансы найти работу у выпускников вузов повышаются на 25 процентов [Электронный ресурс]// Российская газета. Федеральный выпуск. № 6117 (141). URL: https:// rg.ru/2013/07/02/vkus.html (дата обращения: 23.12. 2015). 
Качество образования [Электронный ресурс] // Career.ru. URL: https://career.ru/article/12288 (дата обращения: 18.01.2016).

Аавыдова, Н. И. (1999) Индивидуальная ситуация на рынке труда и стратегия занятости // Общественные науки и современность. № 3. С. 13-24.

Аудина, М. М., Семенова, С. $\Lambda$. (2015) Технологии трудоустройства : учеб. пособие. Екатеринбург : ИзА-во Рос. гос. проф-пед. ун-та. 180 с.

Зарплата 2013 [Электронный ресурс] // SuperIob.ru. URL: http://www.superiob.ru/research/zarplata-vypusknikov/2013/ (дата обращения: 23.12. 2015).

Зубок, Ю. А., Ростовская, Т. К., Смакотина, Н. А. (2016) Молодежь и молодежная политика в современном российском обществе. М. : ИТА «Перспектива». 165 с.

Резник, С.А. (2002) Комплексная система непрерывной практической подготовки и трудоустройства студентов в период обучения в вузе: разработка и реализация цикла инновационных образовательных проектов. Пенза : ПГАСА. 220 с.

Чередниченко, Г. А. (2004) Молодежь России: социальные ориентации и жизненные пути (опыт социологического исследования). СПб. : ИзА-во Русского Христианского гуманитарного ин-та. 504 с.

Aата поступления: 20.04.2016 2.

\section{SENIORS' CAREER PLANS AND THE DEMANDS OF THE LABOR MARKET: THE ISSUE OF COMPLIANCE}

\section{S. KOROTKOVA}

(MOSCOW UNIVERSITY FOR THE HUMANITIES)

At the moment, young professionals enter the labor market at its crisis point, aggravated by job cuts, wage detention, shrinking labor hours and other violations of labor laws. Further augmented by exorbitant requirements advanced by employers, the process of job search and getting employment is a harsh trial which requires special skills for an applicant to succeed.

At the end of the academic year 2015 the Center for Graduate Employment Assistance of Moscow University for the Humanities surveyed seniors' career plans and prospects. The participants were 168 students in the final year of their bacherlors' program. An analysis of the poll allowed us to outline the basic issues which may make it difficult for the graduate to get a job they want.

For a substantial part of respondents, work remains an important factor of self-identification. Half of them plan to get a job in the field of their studies and already have some work experience in this field by the time they graduate.

A specific feature of labor motivation for contemporary youth is its instrumentalization. For a third of the respondents, salary as a factor in job search trumps the job contents. We have discovered a correlation between the desired salary and the field of study: those who completed the program in international relations expect the highest post-graduation salaries, but actually find it more difficult to get a job.

Excessive ambitiousness combined with a lack of job experience, absence of positive vibes, systemic thinking and any understanding of one's position at workplace - those are the main reasons for denying employment. Some respondents consider their own time and comfort more valuable in job search than expectation of an attractive job or professional development.

The outcomes of our survey show that seniors in bachelors' programs are largely unprepared for job search: many of them do not understand what is happening in the job market and are unaware of the employers' requirements. To help remedy this issue, the Center for Graduate Employment Assistance has been set up in Moscow University for the Humanities. 
Keywords: employment; university graduates; university students; university seniors; career choice; labor market; career strategy

\section{REFERENCES}

Letom shansy naiti rabotu u vypusknikov vuzov povyshaiutsia na 25 protsentov. Rossiiskaia gazeta, No. 6117 (141) [online] Available at: https://rg.ru/2013/07/02/vkus.html (access data: 23.12. 2015). (In Russ.).

Kachestvo obrazovaniia. Career.ru [online] Available at: https://career.ru/article/12288 (access date: 18.01.2016). (In Russ.).

Davydova, N. I. (1999) Individual'naia situatsiia na rynke truda i strategiia zaniatosti. $O b$ shbestvennye nauki i sovremennost', No. 3, pp. 13-24. (In Russ.).

Dudina, M. M. and Semenova, S. L. (2015) Tekbnologii trudoustroistva : ucheb. posobie. Ekaterinburg, Ros. gos. prof-ped. un-t. 180 p. (In Russ.).

Zarplata 2013. SuperJob.ru [online] Available at: http://www.superjob.ru/research/zarplata-vypusknikov/2013/ (access date: 23.12. 2015). (In Russ.).

Zubok, Yu. A., Rostovskaia, T. K. and Smakotina, N. L. (2016) Molodezb' i molodezhnaia politika $v$ sovremennom rossiiskom obshbestve. Moscow, ITD Perspektiva. 165 p. (In Russ.).

Reznik, S. D. (2002) Kompleksnaia sistema nepreryvnoi prakticheskoi podgotovki $i$ trudoustroistva studentov $v$ period obucbeniia $v$ vuze: razrabotka $i$ realizatsiia tsikla innovatsionnykb obrazovatel'nykh proektov. Penza, PGASA . 220 p. (In Russ.).

Cherednichenko, G. A. (2004) Molodezb' Rossii: sotsial'nye orientatsii i zbiznennye puti (opyt sotsiologicheskogo issledovaniia). St. Petersburg, Russkii Khristianskii gumanitarnyi in-t. 504 p. (In Russ.).

Submission date: 20.04 .2016$.

Короткова Марина Сергеевна - старший преподаватель кафедры социологии, директор Центра содействия трудоустройству выпускников Московского гуманитарного университета. Адрес: 111395, Россия, г. Москва, ул. Юности, д. 5, корп. 3. Тел.: +7 (926) 992-81-24. Эл. адрес: mkorotkova@mosgu.ru . Научный руководитель - A-р социол. наук, проф. Н. А. Селиверстова.

Korotkova Marina Sergeevna, Senior Lecturer, Department of Sociology, Moscow University for the Humanities; Director, Centre of Graduate Employment Assistance. Postal address: Bldg. 3 , 5 Yunosti St., 111395 Moscow, Russian Federation. Tel.: +7 (926) 992-81-24. E-mail: mkorotkova@mosgu.ru. Research supervisor - Doctor of Sociology, Professor N. A. Seliverstova. 